\title{
Performance of a Solidification Furnace Developed for Sounding Rockets
}

\author{
Chen Y. An - Cesar Boschetti • Manuel F. Ribeiro • \\ Rafael C. Toledo $\cdot$ Filipe E. Freitas • Iraja N. Bandeira
}

Received: 14 February 2011 / Accepted: 5 May 2011

(C) Springer Science+Business Media B.V. 2011

\begin{abstract}
Brazil has a Microgravity Program mainly based on experiments using sounding rockets. This paper presents a brief account of the Program and the experiments made on the Brazilian rockets. Up to now three missions carrying a total of 26 experiments were made. In all flights a fast solidification furnace, capable of producing temperatures up to $900^{\circ} \mathrm{C}$, was tested with semiconductor and metal alloys. This paper describes the construction and the performance of that furnace during the last parabolic flight, occurred in 2010. The solidification furnace is now qualified and ready to be used by other institutions in sounding rocket flights.
\end{abstract}

Keywords Suborbital flights • Solidification furnace $\cdot$ VSB-30 sounding rocket $\cdot$ Brazilian microgravity program

C. Y. An · C. Boschetti - M. F. Ribeiro - R. C. Toledo ·

F. E. Freitas · I. N. Bandeira ( $\square)$

Laboratório Associado de Sensores e Materiais, Instituto Nacional de Pesquisas Espaciais,

Av. dos Astronautas, 1758, 12227-010,

São José dos Campos, SP, Brazil

e-mail: iraja@las.inpe.br

C. Y. An

e-mail: chen@las.inpe.br

\section{Introduction}

The Brazilian Microgravity Program was established in 1998 by the Brazilian Space Agency (AEB), aimed to provide a regular sequence of flight opportunities to the Brazilian scientific community to perform experiments and to test hardware facilities in microgravity environment.

The Program supports the Brazilian microgravity activities by selecting and following the experiments since their initial design phases up to the flight mission, given also partial financial support for the approved projects (http://www.aeb.gov.br).

Their activities are technically assisted by institutions such as the Brazilian Space Research Institute (INPE) and the Aeronautical and Space Institute (IAE).

The Microgravity Program contemplates missions on ISS/Soyuz and on Brazilian made sounding rockets. Up to now only one flight, described elsewhere (Bandeira et al. 2007), was made at ISS in 2006, carrying eight experiments and the first Brazilian astronaut.

The first parabolic flight was in 2002 and eight microgravity experiments were selected by the Program 1st Announcement of Opportunity (AO), embracing areas such as biology, material sciences and transport phenomena. During the 4 min flight, high speed telemetry and real time high resolution digital video were offered. Into the proposed scenario, the payload would land at the 
Fig. 1 Brazilian sounding rockets made at IAE. The VS-30 was used in the 1st AO and the VSB-30 was employed in the 2nd and 3rd AO's. The VSB-30 actual picture was from the 3rd AO, showing the cooling bags used for biological experiments during the waiting time in the launching platform

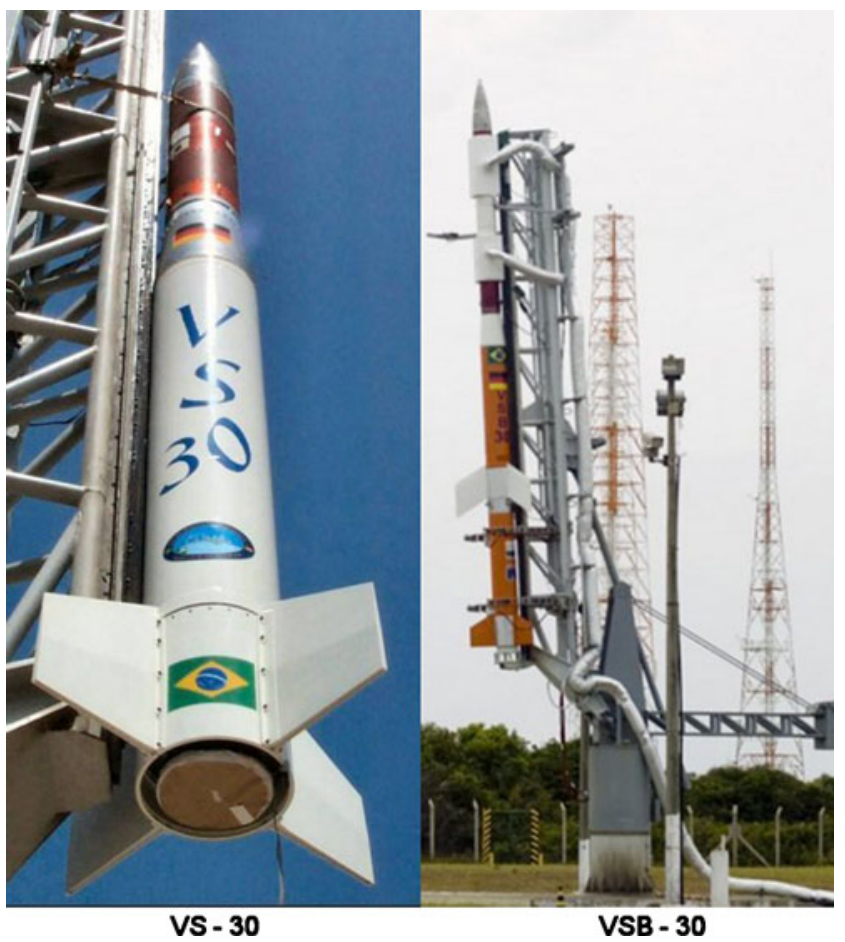

sea with the aid of parachutes and be recovered by helicopter.

The experiments were launched by a one-stage Brazilian VS-30 sounding rocket (3 to $4 \mathrm{~min}$ of microgravity), made by IAE, from the Alcântara Launching Center. Unfortunately, a failure resulted in the platform loss at the sea, making impossible the experiments recovery. A second flight was done in 2007 and a third in 2010 with a more powerful two-stage sounding rocket denominated VSB-30 (6 to 8 microgravity minutes). The VSB30 is capable of transporting payloads with mass up to $400 \mathrm{~kg}$ during about $360 \mathrm{~s}$ in a ballistic flight above $110 \mathrm{~km}$. The rocket transports a payload, based in the TEXUS technology, made by DLR/MORABA in cooperation with IAE, used to monitoring the flight, into a nominal trajectory (Corrêa et al. 2005).

Figure 1 shows these rockets, while Table 1 summarizes some of the main characteristics of the Brazilians operational rockets for microgravity purposes.

Figure 2 shows the payload that is used to carry the microgravity experiments on the VSB-30
Table 1 Rockets characteristics without payload

\begin{tabular}{llllll}
\hline Rocket & \multicolumn{3}{l}{ Rocket stage characteristics } & & \\
\cline { 2 - 6 } & VS-30 & VSB-30 & VS-30/Orion & \\
\hline Stage & - & $1^{\text {st }}$ & 2nd & 1 st & 2nd \\
Rocket motor & S30 & S31 & S30 & S30 & Orion \\
Length (mm) & 4094 & 3310 & 4094 & 3700 & 2657 \\
Diameter (mm) & 557 & & & & 356 \\
Mass (kg) & 1183 & 995 & 1236 & 1166 & 425 \\
Microgravity time & 180 & 450 & & 450 & \\
$\quad$ above 110 km (s) & $300 \mathrm{~kg}$ payload & $300 \mathrm{~kg}$ payload & $200 \mathrm{~kg}$ payload \\
Burning time (s) & 19 & 12 & 19 & 19 & 22 \\
Action time (s) & 28 & 18 & 28 & 28 & 26 \\
Apogee (km) & 150 & 330 & & 330 & \\
\hline
\end{tabular}




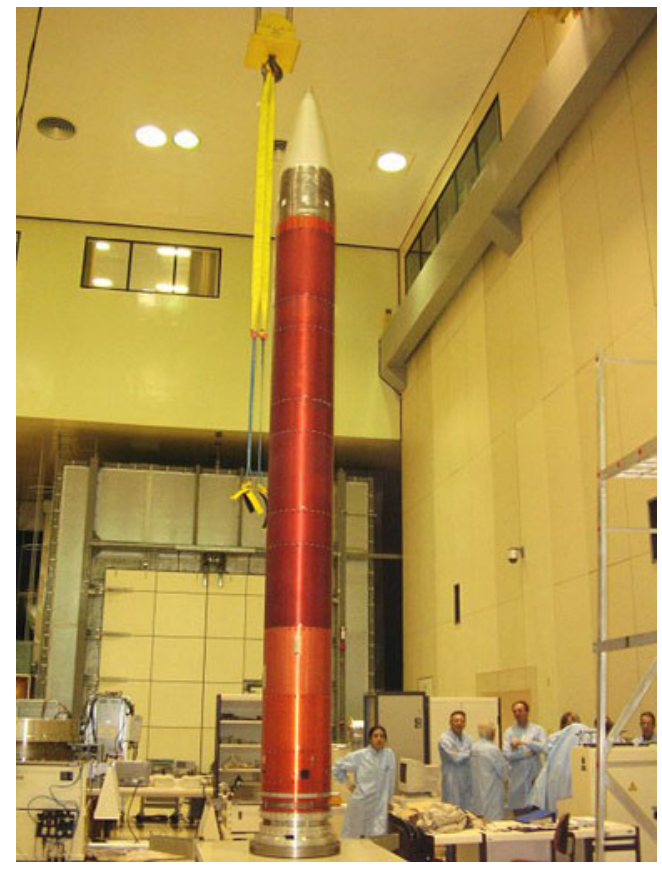

Fig. 2 Microgravity experiments payload at INPE's Tests and Integration Laboratory

rocket. After the parabolic flight it fells on the sea aided by parachutes and is recovered by Brazilian Air Force helicopters.

\section{Solidification Furnace}

The objective was to project, construct and qualify a compact furnace as a permanent facility to the sounding rockets microgravity program. The proposal was made by a group of the Associate Laboratory of Sensors and Materials (LAS) of the Brazilian Space Research Institute, and the idea was to have a several user furnace facility for the Brazilian groups that worked in that area. The furnace purpose is to melt and solidify metals and semiconductor alloys with fusion point up to $900^{\circ} \mathrm{C}$. The furnace should be capable of a fast cooling, compatible with the short microgravity times of suborbital flights, in order to solidify sample up to $10 \mathrm{~mm}$ diameter and up to $120 \mathrm{~mm}$ length.

The tubular furnace is heated and controlled from the ground through the rocket umbilical cable until it reaches the desired temperature. After launch the temperature is kept by thermal inertia. When the microgravity environment is reached, a signal starts the movement of the hot part of the furnace and a fast sample cooling is obtained. The experiment temperature is monitored by two thermocouples and their signals are stored in an internal data-logger as well as sent to ground by telemetry.

The exploded drawing of the furnace is shown on Fig. 3. It comprises the tubular furnace itself made of stainless steel, having $110 \mathrm{~mm}$ of diameter and $200 \mathrm{~mm}$ length. The materials processing chamber is a ceramic tube with $20 \mathrm{~mm}$ diameter, running along the center of the whole furnace. The upper $120 \mathrm{~mm}$ part of the ceramic tube is involved by a shielded electrical resistance and quartz fiber is employed as thermal insulation. The remaining resistance free portion produces a thermal gradient in the order of $40^{\circ} \mathrm{C} / \mathrm{cm}$. There is an external structure holding the furnace, permitting it's up and down movement with the aid

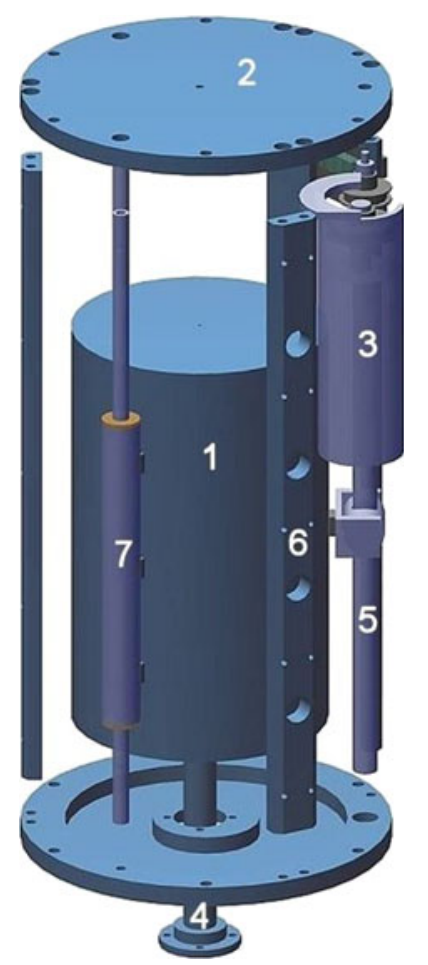

Fig. 3 Exploded view of the solidification furnace: 1 furnace; 2 - top of the external structure; 3 -driving motor; 4 - sample holder; 5 - jackscrew; 6 - structural bars; 7 sliding guide bars 
of an electric motor. This structure also supports a stainless steel sample holder tube placed inside the ceramic cavity. The system has a total diameter of $180 \mathrm{~mm}$ and a total length of $340 \mathrm{~mm}$, weighting $12 \mathrm{~kg}$.

Figure 4 shows the furnace in the two positions described above. During ground and ascending rocket phase the furnace is at the bottom position, completely involving and heating the sample. As soon as the microgravity environment is reached, the motor drives de furnace to the upper position in less than $8 \mathrm{~s}$, leaving the sample exposed to cool down.

At the side of the solidification furnace appears the electronics control box. It contains a datalogger for the two type $\mathrm{K}$ thermocouples, batter-

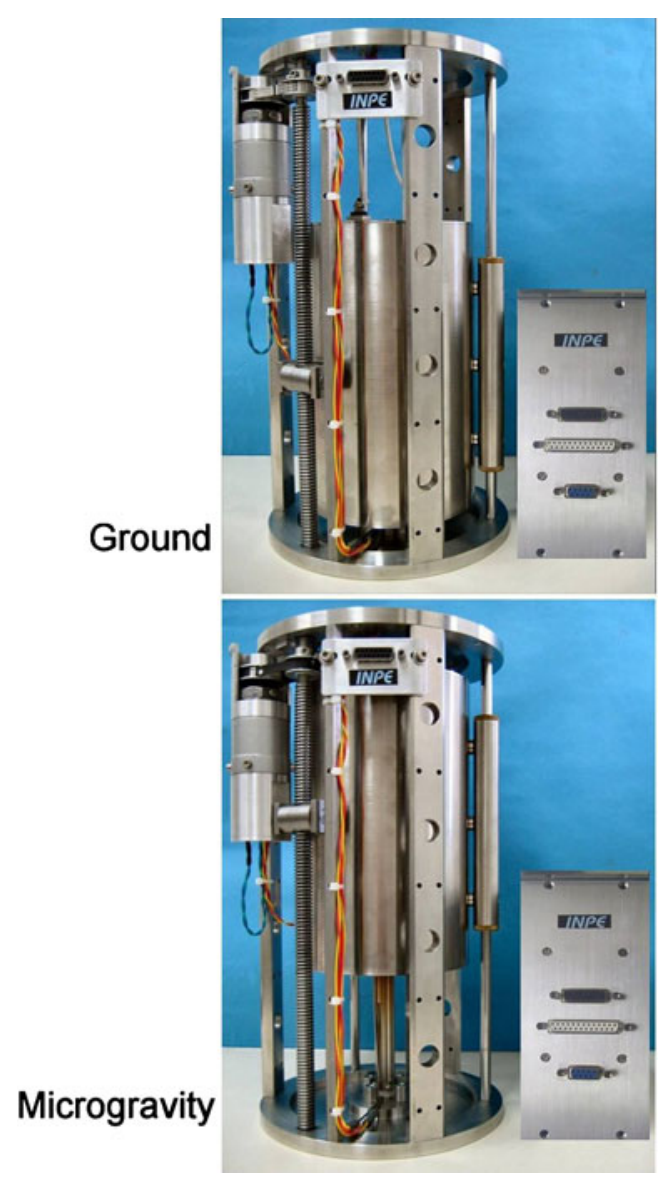

Fig. 4 Solidification furnace in its two working phases: at the bottom heating the sample during ground and ascending periods, and at the top permitting a fast sample cooling during microgravity ies for the furnace drive motor, timer for motor stopping, amplifier for telemetry temperature signals and the circuit for the control thermocouple connected to the controller unit and a $110 \mathrm{DCV}$ source that powers the furnace from the ground, providing a temperature stability of $\pm 1{ }^{\circ} \mathrm{C}$.

\section{The Maracati Mission}

The third AO flight had taken place on December, 2010 and was codenamed Maracati.

A VSB-30 rocket carried ten microgravity experiments from Brazilian universities and research centers. The apogee was $242 \mathrm{~km}$ and the total flight time $18 \mathrm{~min}$, from which $6 \mathrm{~min}$ in microgravity. The payload fell on the sea and was rescued about $1 \mathrm{~h}$ later.

Among the experiments was the Solidification Furnace described above made at the LAS/INPE. The furnace was projected, constructed and fully qualified for space flight at INPE's facilities.

In this flight a solidification experiment with two eutectic alloys was carried out. The eutectic composition $(10.9 \mathrm{~Pb}$ at.\%) of the $\mathrm{PbTe}$ alloy with a fusion point of $410^{\circ} \mathrm{C}$, and the eutectic composition (26.1 $\mathrm{Pb}$ at.\%) of the $\mathrm{PbSn}$ alloy, fusion point of $183^{\circ} \mathrm{C}$, were used.

Each sample, with $13 \mathrm{~g}$ mass, was sealed under vacuum within a quartz ampoule with $60 \mathrm{~mm}$ length and $10 \mathrm{~mm}$ diameter shown on Fig. 5 and the furnace temperature gradient is shown on Fig. 6.

The ampoules were fitted inside the stainless steel tube sample holder and the furnace was heated in the ground to $500^{\circ} \mathrm{C}$, using the rocket umbilical cable, $30 \mathrm{~min}$ before launch. The sample temperatures were monitored by the on-board data-logger as well as by telemetry.

The microgravity level attained was in the order of $10^{-4} \mathrm{~g}$ which was enough to cause predominance of Marangoni convection over the thermal and constitutional gravitational dependent convections. That will allow the study of the superficial tension influence in the $\mathrm{PbTe}$ and $\mathrm{PbSn}$ eutectic alloys.

The samples will be analyzed by several techniques such as x-ray diffraction (XRD), scanning electron microscopy, $\mathrm{x}$-ray dispersive energy spec- 
Fig. 5 Eutectic

$\mathrm{Pb}_{10.9} \mathrm{Te}_{89.1}$ and $\mathrm{Pb}_{26.1} \mathrm{Sn}_{73.9}$ ampoules after the microgravity flight

Fig. 6 Temperature gradient of the solidification furnace showing the samples quartz ampoules position inside the sample holder

Fig. 7 Telemetry data of the solidification furnace thermal cycle during the microgravity flight
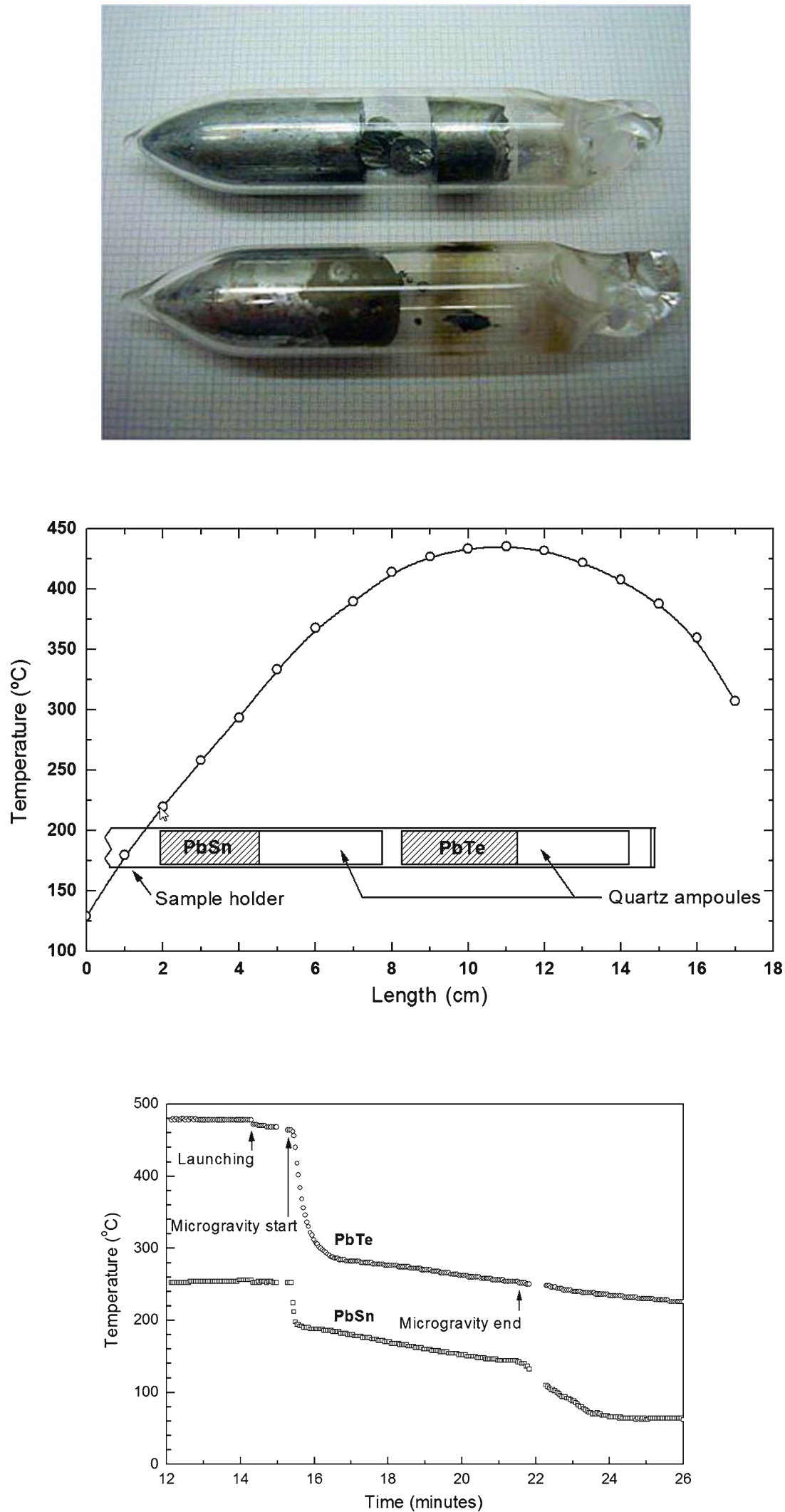
Fig. 8 Module

temperature as measured

by two thermocouples

TC1 and TC2 located at

the top and bottom

module plates,

respectively

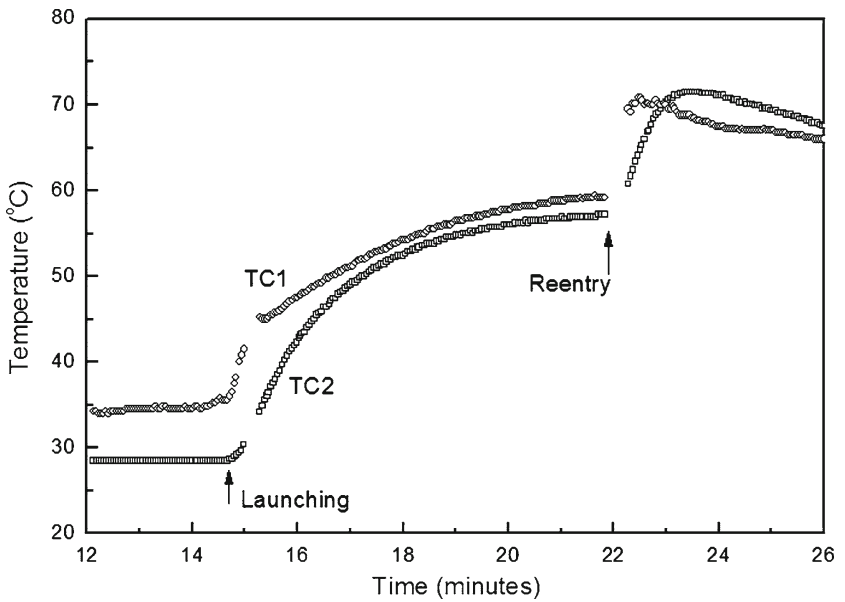

the payload feel and floated in the sea and was later recovered by a Brazilian Air Force diving team.

The telemetry data for the furnace thermal cycle is shown on Fig. 7 for both samples.

The cycle behavior was as expected, the furnace temperature having a small drop of about $10^{\circ} \mathrm{C}$ during the rocket ascending due to the one minute without power. Reaching microgravity, as soon as the furnace moved to the upper position, the temperature drop was of $150^{\circ} \mathrm{C}$ in $30 \mathrm{~s}$ for the $\mathrm{PbTe}$ alloy, allowing the fast cooling needed for the eutectic $\mathrm{Pb}_{10.9} \mathrm{Te}_{89.1}$ and $\mathrm{Pb}_{26.1} \mathrm{Sn}_{73.9}$ solidification experiment.
Fig. 9 Solidification furnace just after the microgravity flight

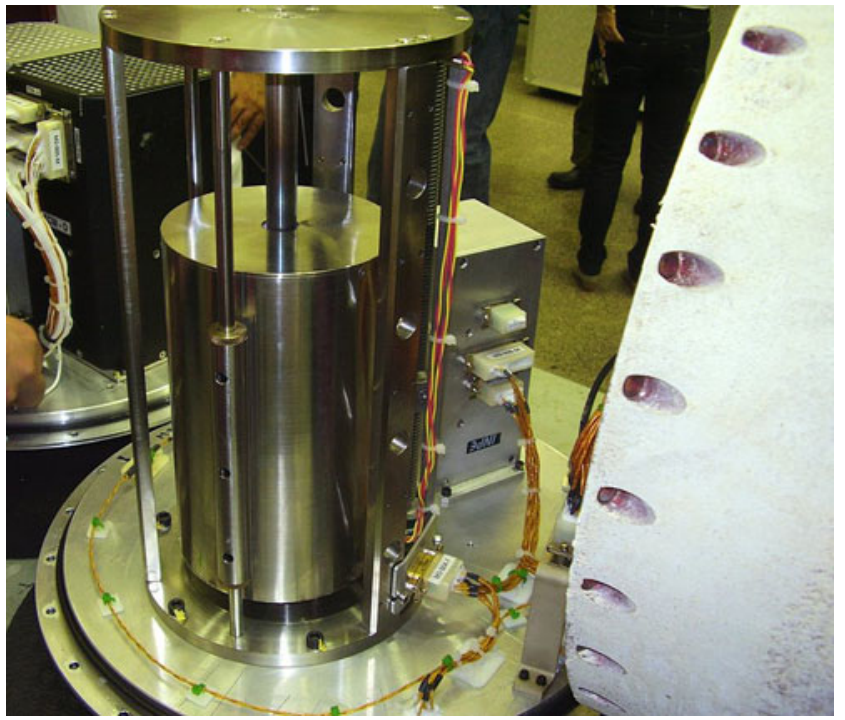


One of the concerns was the overall module temperature were the furnace was located. Once several experiments, including biological ones, were nearby, the insulation has to be good enough to keep the module external walls inside the acceptable limit.

Two thermocouples TC1 and TC2 located at the module top and bottom plates, respectively, measured the temperature that the furnace caused to the encasing environment.

As can be seen by the graph on Fig. 8, during the ground phase the maximum temperature inside the module, on the top plate were the furnace was attached, was $35^{\circ} \mathrm{C}$, well inside the limits. After launching and reentry the temperature increased to around $70^{\circ} \mathrm{C}$ due to the atmospheric friction.

Figure 9 shows the furnace in the system upper part position just after the flight. The steel tube, now outside the furnace, is the sample holder containing the samples. In the right side, the scorched payload module.

\section{Conclusions}

The Solidification Furnace, provide by INPE to the Brazilian sounding rocket program, is now qualified and ready to be used by other groups that are interested in melting and solidifying semiconductor and metallic alloys up to $900^{\circ} \mathrm{C}$ in microgravity.
Already following this policy, the INPE's furnace was used to process experiments from the Pernambuco Federal University in the two first flights. In a vacant place inside the sample holder, an experiment for studying the thermal migration of metallic nanoparticles in a vitreous material (Oliveira et al. 2002 and 2007), was carried out together with narrow gap semiconductors experiments from LAS/INPE (Bandeira et al. 2002 and 2007).

Acknowledgements The authors are grateful to the Brazilian Space Agency for supporting the present project.

\section{References}

Bandeira, I., Bogossian, O., Corrêa, F.: Centenary mission-first Brazilian microgravity experiments at ISS. Microgravity Sci. Technol. XIX-5/6 (2007)

Bandeira, I.N., An, C.Y., Boschetti, C., Ribeiro, M.F., Ferreira, F.A., Peixoto, J.C., Silva, S.A.: Forno Multiusuário para Solidificação (FORMU-S). http://www. aeb.gov.br/download/microgravidade/Relatoriopag_ 61_74_Iraja.pdf (2002 and 2007).

Corrêa, F., Mussi, R., Humann, M., Calderan L., Bandeira, I.: Brazilian microgravity program: challenges and perspectives. In: Proceedings of the 17th ESA Symposium on European Rocket and Balloon Programmes and Related Research, Norway. http://adsabs.harvard.edu/ abs/2005ESASP.590..509D (2005)

Oliveira, P.S.C., Pedrosa, G.G.: Difusão Térmica de Nanopartículas Metálicas em Materiais Vítreos. http://www. aeb.gov.br/download/microgravidade/Relatorio_pag75_ 82_Petrus.pdf (2002 and 2007). 